\title{
Environment Disease Relationship and Its Impact on Household Economy
}

\author{
Uttam Paudel* \\ Environmental Health Economist, Tribhuvan University, Nepal
}

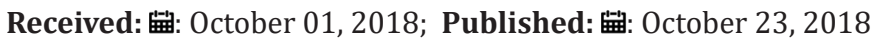

*Corresponding author: Uttam Paudel, Environmental Health Economist, Tribhuvan University, Kathmandu-3, Bairochan Marg 37/7, Nepal

\begin{abstract}
A massive number of Literature is accessible focusing only on the general concern of climate change ignoring the cost valuation of the association between environmental change and human health. Establishment of environment-disease relationship leading to economic consequences is found timely and apposite research at this moment. Therefore, this paper aims to establish environmental-health relationship and its impact on household economy through cost of illness in western part of Nepal. Time series analytical economic evaluation design is employed using secondary data to establish environment-disease relationship with the help of ordinary least square, being based on the econometric theory. The results divulge that environmental variables such as extreme summer temperature warm winter temperature and population density are in favor to increase the disease prevalence, whereas, increasing winter rainfall, immunization coverage and vitamin A coverage among children seemed to reduce the disease prevalence in western Nepal. Similarly, disease-environment relationship showed that $1^{\circ} \mathrm{C}$ increase in temperature increases the disease prevalence at least by $5 \%$ in the existing rate of prevalence in western Nepal, controlling other variables.
\end{abstract}

Above relation in sensitivity analysis assuming linear relationship showed that every $0.5^{\circ} \mathrm{C}$ increase in temperature leads to increase in cost of illness at household level at least by NPR 77.7 million in western Nepal. Establishment of environment-disease relationship concludes that adaptation measures for protecting from summer extreme temperature is an urgent action needed for disease reduction in western Nepal. Besides, controlling population, extension of immunization and vitamin A programs to the children are also seemed to reduce illness in western Nepal. Therefore, recommendations are made accordingly.

Keywords: Western Nepal; Health; Environmental Change; Cost of Illness

Abbreviations: OLS: Ordinary Least Square; DHM: Department of Hydrology and Meteorology; CBS: Central Bureau of Statistics; OPD: Out Patient Department

\section{Introduction}

Environmental variation can expedite alterations in the geographical range, seasonality and prevalence of climatesensitive diseases; and can upturn the affliction of under-nutrition due to changes in water availability, biodiversity [1] and agroproducts attendant with an erratic climatic vulnerability [2,3]. Environmental health is considered as the aspect of communal health concerned with all the factors, statuses, and conditions in the environment or ambiances of humans that can put forth an influence on human health and wellbeing [4]. Environmental perils are in charge for about one-fourth of the total burden of disease worldwide, and for worryingly attributing to communicable diseases in developing countries and non-communicable diseases in developed countries [5]. The disease burden influences with the result of diverse environmental, social and behavioral risk factors [6]. With the increase in the global population and the rising the amount of general and toxic waste being generated daily by each household but not properly managed, especially excreta and other liquid and solid waste from households and the community are a serious health hazard and lead to the spread of infectious diseases [7].

Environmental threats to the human health in South Asia including Nepal are myriad, and include the classic infectious disease hazards: pneumonia, dengue, malaria, dysentery, measles, AIDS, and tuberculosis [8-10]. However, the past studies innocuously using household surveys to analyze the health impacts of environmental conditions are with biased estimate, improper sample size, sample selection bias and errors in measuring environmental condition which aim to obtain unbiased estimates of these impacts with high precision [11]. Minimizing the adverse effect of environmental change- specifically climate change on human health has set in 
priority among sustainable development goals. As per the goal, all the countries must achieve the environmentally sound management of all wastes throughout their life cycle, in accordance with agreed international frameworks, and significantly reduce their release to air, water, and soil [12]. Nevertheless, any clear framework for the management of health system with reference to the environmental change in Nepal has not been established owing to the unavailable evidence over major environmental determinants for disease prevalence and cost of illness caused by environment-disease association, one of the motivating factors for stakeholders working on environmental health [6]. This study therefore mainly aims to establish Nepal based economic analysis of environment-health relationships with cost of illness in western Nepal addressing the potential gap in the literature. The whole procedure is compressed in conceptual framework (Figure 1).

\section{Methods and Materials}

\section{Research Design}

Time series analytical economic evaluation design is employed using secondary data. Based on the objective of the study, secondary data are treated to obtain the environment-health relationship, controlling health system variables, obtained from Department of Hydrology and Meteorological and other relevant published resources; to investigate and estimate disease-environment relationships, maintaining both qualitative and quantitative aspects. Collected data were entered into the SPSS and transform into STATA for the analysis.

\section{Study Setting and Design}

Time series analytical study design is for the establishment of the relationship by ordinary least square (OLS) method using twenty years secondary data from 1997 to 2016 (optimum available) focusing only the data of mid-western development region of Nepal which are hardly available at different departments. The selection of the region is because of relatively high disease occurrence in the last five years and the key area for primary data collection in this research. Health data were collected from Department of Health Service annual reports that encompass all sorts of data related to hospital and other health services in national, regional and district level of Nepal, and meteorological data from Department of Hydrology and Meteorology (DHM) covering all the stations of mid-western development regions; and other population data from central bureau of statistics (CBS). The main purpose of this research is to explain the environment-disease prevalence relationship establishment procedure to reach to estimate cost of illness.

Disease prevalence is the proportion of the population at risk affected at any point in an interval of time. Here, disease prevalence is the dependent variable. Firstly, net out-patient department (OPD) visits (including repeated cases) due to disease only were separated from total OPD visits of mid-western region of Nepal. Then, as per the definition, disease prevalence is calculated by dividing Net OPD visits by total population of the region. Disease prevalence might be affected by other health system independent variables which are available with data and included in this research are number of health institution, coverage of vitamin A to the children, change in malnourished child, health expenditure at 2016 price and population density. All the independent variables are discrete in nature. Most importantly, environmental variables or climatic indices: temperature and rainfall are used as independent variables. Seasonal extreme temperature may influence the disease prevalence rate.

So, maximum summer temperature was selected from three months June, July and August, and summer minimum temperature was selected the minimum temperature of the same selected month for each year. Similarly, winter minimum temperature from November, December and January was selected with maximum winter temperature of the same month. Regarding rainfall, first, year was divided into four quarters with three months in each quarters: winter rainfall (starting with January, February and March), then pre-monsoon, monsoon and post monsoon. All the average of three months rainfall with seasonal effects were made free from seasonal effects by dividing the average rainfall by average of coefficients. The major hypothesized variables are described in the following (Table 1).

Table 1: Description of hypothesized variables.

\begin{tabular}{|c|c|c|}
\hline Variables Name & Description & Expected sign \\
\hline S_MA_TE & $\begin{array}{l}\text { Summer maximum temperature } \\
\text { (Increasing) }\end{array}$ & + ve \\
\hline W_MA_TE & $\begin{array}{l}\text { Winter maximum temperature } \\
\text { (Increasing) }\end{array}$ & +ve or -ve \\
\hline Winter Rainfall & $\begin{array}{l}\text { Decreasing rainfall }(\mathrm{mm}) \text { in the } \\
\text { winter season }\end{array}$ & -ve \\
\hline Vit_A_Child & $\begin{array}{l}\text { Percentage coverage of vitamin A } \\
\text { to the children }\end{array}$ & -ve \\
\hline Malnu_child & $\begin{array}{l}\text { Coverage of Immunization to the } \\
\text { children }\end{array}$ & -ve \\
\hline Pop_den & Population density & +ve \\
\hline No_H_Insti & Number of health institution & -ve \\
\hline
\end{tabular}

\section{Econometric Treatment}

After the data became ready for the analysis, ordinary least square method is used to identify the environment-disease relationship with the help of following model. Disease prevalence $=\mathrm{f}$ (Environmental variables + health system variables + other control variables) ........ (1)

More specifically, the OLS regression equation can be written as,

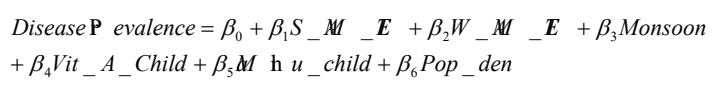

Where, S_MA_TE = summer maximum temperature

W_MA_TE $=$ winter maximum temperature

Monsoon $=$ Monsoon rainfall

Vit_A_Child $=$ Coverage of vitamin A to the children

Malnu_child $=$ Number of malnourished child

Pop_den = Population density

$\beta s=$ Coefficients 
After the establishment of environment-disease relationship, economic cost of illness for environmental hazards were estimated with some sensitivity analysis based on the Paris declaration of $2^{\circ} \mathrm{C}$ increase in temperature by the end of $21^{\text {st }}$ century.

\section{Results}

The relationship between environment and human diseases are intricately linked as said by WHO: "Environmental health addresses all the physical, chemical, and biological factors and all the related factors impacting behaviors that can potentially affect health [13]. This study is mainly concerned with the identification of environmental and health system variables influencing disease prevalence, and relationship establishment between environment and human disease prevalence by the use of time series data from 1997 to 2016. First, two models are set with their results and then with the relation of environmental indicator on human health, an economic impact of the relation is explained in detail.

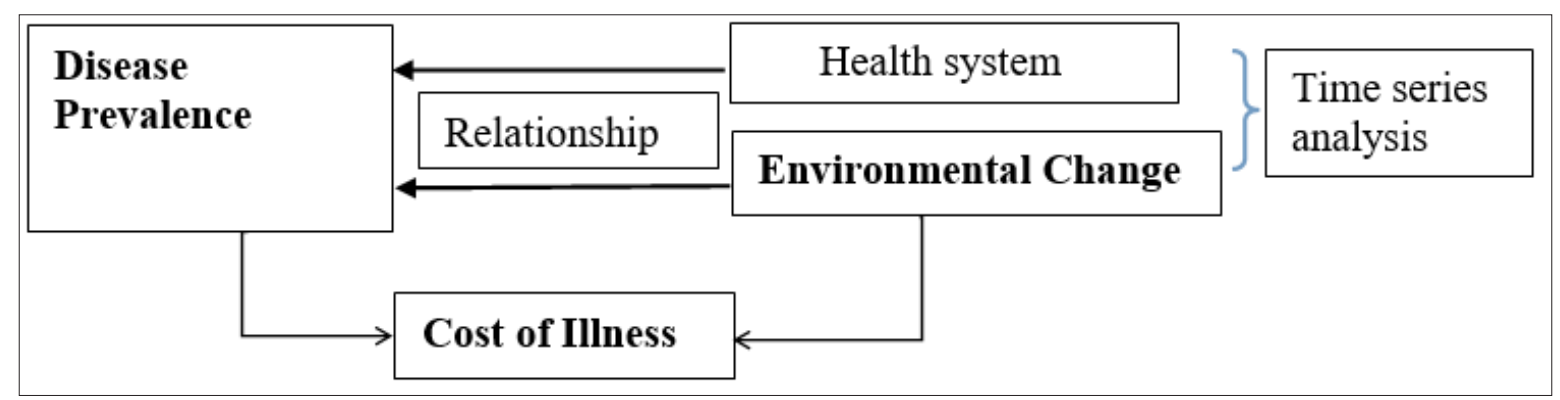

Figure 1: Conceptual Framework.

\section{Results of Descriptive Analysis}

To begin with some descriptive analysis, per capita health expenditure is found in increasing trend in mid-western region of $\mathrm{Ne}$ pal as shown in Figure 2. Similarly, immunization coverage is also increasing continuously. Along with this, number of malnourished children is dramatically decreasing in this region. As mentioned in methodology section, disease prevalence is dependent continuous variable, and temperature, rainfall and other control variables are independent variables. Because of co-linearity problems even af- ter some adjustment on them, only few variables are included in the analysis which are free from heterogeneity and co-linearity problems. In this particular situation, model I is set for the analysis of disease prevalence affected by environmental factors only and model II explains a total effect of environmental and other control variables on disease prevalence in mid-western development region of Nepal. Both the models are run with OLS regression after the variables made free from co-linearity which is shown in the following correlation matrix in Table 2.

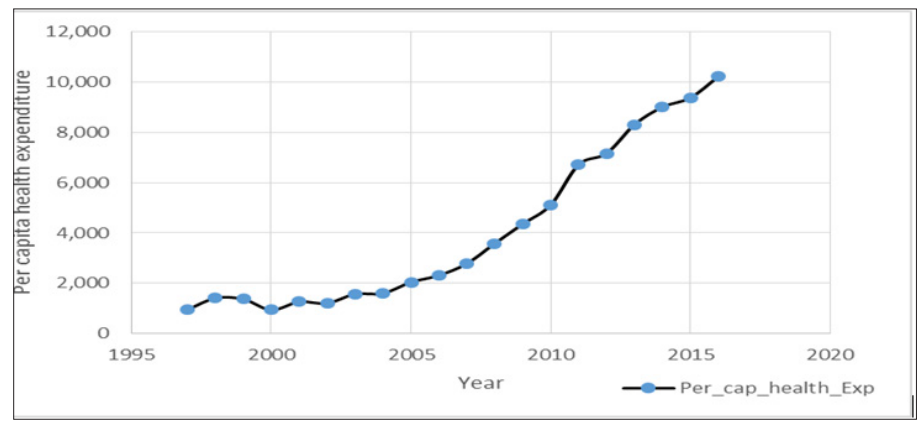

Figure 2: Trend of pre capita health expenditure (NPR) in Nepal.

Table 2: Correlation matrix.

\begin{tabular}{|c|c|c|c|c|c|c|c|c|}
\hline & Dis_pre & S_TE & W_TE & W_Ra & Vit_Chi & Pop_d & Mal_C & H_Ins \\
\hline Dis_pre & 1 & & & & & & \\
\hline S_TE & 0.52 & 1 & & & & & \\
\hline W_TE & 0.22 & -0.21 & 1 & & & & \\
\hline W_Ra & -0.05 & 0.23 & -0.20 & 1 & & & \\
\hline Vit_Chi & 0.07 & 0.05 & 0.23 & 0.15 & 1 & & \\
\hline Pop_d & 0.71 & 0.35 & 0.33 & 0.16 & 0.48 & 1 & \\
\hline Mal_C & -0.55 & -0.41 & -0.48 & -0.11 & -0.43 & -0.43 & 1 \\
\hline H_Ins & 0.57 & 0.34 & 0.32 & 0.23 & 0.43 & 0.44 & 0.47 & \\
\hline
\end{tabular}

Cite this article: Uttam Paudel. Environment Disease Relationship and Its Impact on Household Economy. Biomed J Sci\&Tech Res 10(2)-2018. 
Note: Dis_pre $=$ Disease Prevalence, $\mathrm{S} \_\mathrm{TE}=$ Summer Maximum Temperature, W_TE = Warmer Winter Temperature, W_Ra $=$ Winter Rainfall, Vit_Chi $=$ Coverage of Vitamin A, Pop_d $=$ Population Density, Mal_C = Coverage of Immunization, H_Ins $=$ Number of Health Institution.

\section{Results of OLS Regression}

Table 3 depicts that summer maximum temperature and warmer winter temperature are strongly significant to increase the disease prevalence in mid-western Nepal as per the model I, which is exactly the same results of previous section. Winter rainfall is negatively significant at $10 \%$ level of significant with the inclusion of all non-environmental variables meaning that winter rainfall is another strong factor to influence the disease prevalence. Winter rainfall may help to reduce ambient air pollution and other water contamination in winter season which lead to less prevalence of diseases. But winter maximum temperature became insignificant for the inclusion of other control variables. Here, environmental variables are only strong enough to explain about $41 \%$ of total disease prevalence scenario in western Nepal. This scenario of result ultimately describes increase in temperature and winter rainfall are major climatic components for the disease rampant in western Nepal.

Table 3: Results of OLS regression for disease-environment relationship. Dependent variable: Disease prevalence.

\begin{tabular}{|c|c|c|}
\hline Variables & Coefficients (Model I) & Coefficients (Model II) \\
\hline $\begin{array}{c}\text { Summer maximum } \\
\text { temperature }\end{array}$ & $0.075^{* * *}(0.024)$ & $0.048^{* *}(0.019)$ \\
\hline $\begin{array}{c}\text { Winter maximum } \\
\text { temperature }\end{array}$ & $0.038^{*}(0.023)$ & $0.0292(0.020)$ \\
\hline Winter rainfall & $-0.0003(0.0005)$ & $-0.0006^{*}(0.0003)$ \\
\hline $\begin{array}{c}\text { Percentage of } \\
\text { Vitamin A covered } \\
\text { children }\end{array}$ & & $\left.-0.0007^{* * *}(0.0002)\right)$ \\
\hline Population density & & $0.059^{*}(0.033)$ \\
\hline $\begin{array}{c}\text { Number of } \\
\text { malnourished child }\end{array}$ & & $-0.0003^{* *}(0.0002)$ \\
\hline $\begin{array}{c}\text { Change in health } \\
\text { institution }\end{array}$ & R-squared $=0.41$ & $-0.0008^{* *}(0.0003)$ \\
\hline \multicolumn{2}{|c|}{ R-squared $=0.81$} \\
\hline
\end{tabular}

Note: No of observations: 20

$* * *=p<0.01,{ }^{* *}=p<0.05,{ }^{*}=p<0.1$

Besides, coverage of Vitamin A and increasing immunization to the children are seemed to reduce the disease prevalence. But increasing population density by years and number of health institution are positively significant with negligible effects on disease prevalence. The independent variables in final model (Model II) are seemed to explain the disease prevalence by $81 \%$ which is quite high. From the above result in Table 3, it is true that if temperature is increased by $1{ }^{\circ} \mathrm{C}$, disease prevalence is also increased at least by $4.8 \%$ in the existing rate of prevalence at $5 \%$ level of significant, in western Nepal, controlling other variables. Possibly, if the relation is supposed to be linear between the disease prevalence and temperature then the existing scenario of disease prevalence with its cost of illness is can be estimated with the help of sensitivity analysis (as shown in Table 4).

Table 4: Sensitivity analysis for temperature induced illness and household cost.

\begin{tabular}{|c|c|c|c|c|}
\hline $\begin{array}{c}\text { Rise in } \\
\text { temperature } \\
\text { (0C) }\end{array}$ & $\begin{array}{c}\text { Increase in } \\
\text { OPD visits } \\
\text { (\%) }\end{array}$ & $\begin{array}{c}\text { Marginal } \\
\text { change in } \\
\text { OPD visit }\end{array}$ & $\begin{array}{c}\text { Direct and } \\
\text { indirect cost } \\
\text { of illness (at } \\
\text { NPR 2158 } \\
\text { per episode) }\end{array}$ & $\begin{array}{c}\text { Marginal } \\
\text { cost of illness } \\
\text { (NPR) }\end{array}$ \\
\hline Base case & - & $3,001,320$ & - & - \\
\hline 1 & 4.8 & 144,063 & $310,887,954$ & - \\
\hline 1.5 & 6 & 180,079 & $388,610,482$ & $77,722,528$ \\
\hline 2 & 8 & 240,105 & $518,146,590$ & $129,536,108$ \\
\hline 2.5 & 10 & 300,152 & $647,669,750$ & $129,523,160$ \\
\hline 3 & 12 & 360,158 & $777,221,827$ & $129,552,077$ \\
\hline
\end{tabular}

First the cost of illness for overall disease prevalence is not available in the context of Nepal, however an Indian study [14] has estimated the cost of illness per episode of hospital visit and found that Nepalese rupees 2,158 per episode which is almost equal to the cost of illness from asthma in Nepal [15]. If the cost of illness is estimated in western Nepal based on the Indian estimation because of the similarity in extreme temperature and disease treatment system in India and Nepal as well, a sensitivity analysis can be shown for base case and other scenarios. The base case is taken from the net OPD visits of 2016 (Figure 2). This analysis is based on the linear relationship but can give a figure of cost of illness due to increase in temperature at different scenarios. This shows that every $0.50 \mathrm{C}$ increase in temperature leads to increase in cost of illness at household level at least by NPR 77.72 million in western Nepal.

\section{Discussion}

Prior to the discussion on results of the study, some pitfalls of the study are rationally presented in some points.

a) This study has ignored some major environmental components such as improper land use extreme weather events etc. which might have potential effect on human health because of unavailable data.

b) This study has covered only mid-western Nepal for, which is representative for western Nepal.

Though the study has some pitfalls, this study is strongly able to produce a detail scenario of several evidences over environmentdisease relationships leading to cost of illness at household level in western Nepal. A new information towards the disease environment relationship that $1^{\circ} \mathrm{C}$ increase in temperature increases the disease prevalence at least by $5 \%$ in the existing rate of prevalence, at less than $5 \%$ level of significant, in western Nepal, controlling other variables, shows adaptation measures for extreme temperature is one of the urgent issues for western Nepal. From sensitivity analysis, assuming linear relationship for every $0.5^{\circ} \mathrm{C}$ increase in temperature leads to increase in cost of illness at household level at least by NPR 77.7 million in western Nepal, has assessed a potential future cost possibly induced by environmental degradation. 
Regarding the aim of this study as identified the environmentdisease prevalence relationship; warmer temperature in entire year and decreasing winter rainfall seemed as potential factors as being consistent with some international studies a [16,17] where warmer winter and spring temperature supports the survival of vector borne and other infectious disease pathogens [18]. Conversely. extreme cold winter is supportive for cold diarrhea and asthma [19]. Among the health system variables; reducing malnutrition, coverage of immunization, vitamin A programs and increase in health institutions are seemed potential factors to reduce the disease prevalence. Immunization coverage among infants is seemed major health activity to protect the child at his higher age. This result is consistent with a paper [20] based on the information of tropical regions. Reducing disease prevalence is possible from availability of Vitamin A program among the under 5 children (Figure 3). Moreover, increasing health institutions in the community is also helpful to reduce the disease prevalence because of the availability of timely cure of diseases. Coverage of Vitamin A and other immunization programs to the children stand to reduce the disease prevalence in western Nepal. If the children at small age are well immunized, obviously the child at growing age will have less chance of getting ill that avoid the hospital visit.

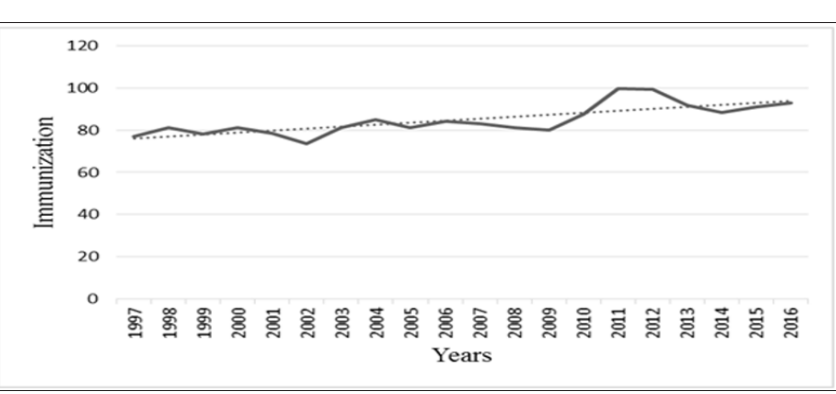

Figure 3: Immunization of $<3$ years children over the study period.

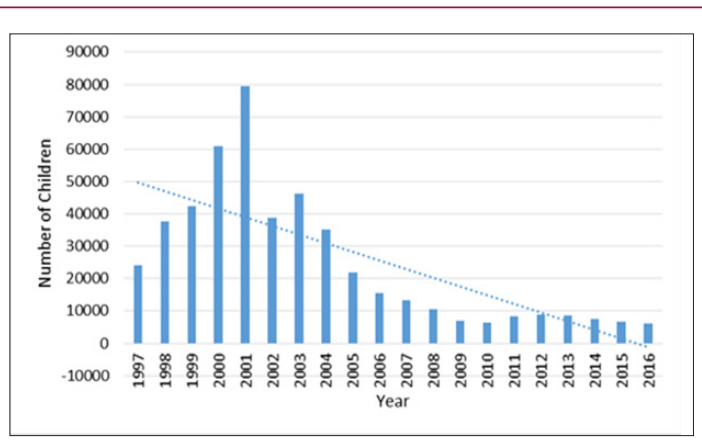

Figure 4: Trend of malnourished children prevalence in western Nepal.

Therefore, timely vitamin $\mathrm{A}$ and other vaccines to the children are beneficial to reduce community health cost. Population density is seemed another cause of disease prevalence. Obviously, increasing population within the same area increases the chance of exposure to disease affected person, beside this, continuous increase in population in certain area might create the scarcity for the resources, leading to the exploitation of resources, which may cause natural imbalance to cause various diseases. Regarding the policy issues, the interconnectedness of human health with the health of the natural environment is an interdependent relationship formally acknowledged by the World Health Organization [21]. This is the high time to take proper action over the protection of environment. Human health is strongly linked to the health of the ecosystem under the natural resources such as soil, water that may results in unprecedented levels of disease emergence which potentially cause severe future impacts on human health. Based on the evidence from this research, Nepal government along with other global cohorts should implement urgent rural adaptation program along with strong coverage of health system improvement programs for the protection of human health from environmental change that has direct negative effect on increasing cost of illness among income poor community of western Nepal.

\section{Conclusion}

This research has developed a comprehensive framework of environment-disease relationship leading to cost of illness based on the secondary data of western Nepal. Establishment of environment-disease relationship concludes that summer temperature is positively associated with disease prevalence, meaning that protecting from summer extreme temperature can be an action for disease reduction in western Nepal. Besides, controlling population, extension of immunization and vitamin A programs to the children are also seemed to reduce illness in western Nepal. The health inaction cost and adaptation costs are seemed gigantic, being over the level of catastrophic payment leading to increasing impoverishment. If the situation of disease prevalence remains same, household health cost might increase to take significant portion of per capita income of the public. At the moment, government initiation for the protection of environment might be timely and possibly successful with the help of locals, leading to the reduction of health hazard cost and more importantly the reduction of health cost as well as obtaining gigantic economic benefit from better health of environment.

\section{References}

1. Young HS, Wood CL, Kilpatrick AM, Lafferty KD, Nunn CL, et al. (2017) Conservation, biodiversity and infectious disease: scientific evidence and policy implications. Philos Trans R Soc B Biol Sci 372: (1722).

2. Fuller CH, Feeser KR, Sarnat JA, O Neill MS (2017) Air pollution, cardiovascular endpoints and susceptibility by stress and material resources: a systematic review of the evidence. Environ Health Environmental Health 16(1): 58.

3. Haines A, Mcmichael AJ, Epstein PR (2000) Environment and health: 2. Global climate change and health. Cmaj 163(6): 729-734.

4. Oiamo TH (2014) Environmental Health Effects of Multiple Exposures: Systemic Risks and the Detroit River International Crossing Study. Electron. Thesis Diss Repos.

5. (2011) Prevention P. WHO Public Health \& Environment Global Strategy Overview: 1-11.

6. Paudel U (2018) Review of Effects of Environmental Change on Human Health. American Journal of Environmental Sciences 14 (3): 95-109. 
7. Alam P, Ahmade K (2013) Impact of Solid Waste on Health and the Environment. Int J Sustain Dev 2: 165-168.

8. (2017) WHO South-East Asia 6: 1-98.

9. (2012) Zuckerman JN. Infectious diseases: a geographic guide. Travel Med Infect Dis p. 520.

10. Bonjour S, Adair Rohani H, Wolf J, Bruce NG, Mehta S, et al. (2013) Solid Fuel Use for Household Cooking: Country and Regional Estimates for 1980-2010.121(7): 784-790.

11. Mendelsohn R, Olmstead S (2009) The Economic Valuation of Environmental Amenities and Disamenities: Methods and Applications. Annu Rev Environ Resour 34: 325-347.

12. Prüss Ustün A, Wolf J, Corvalán C, Neville T, Bos R, et al. (2016) Diseases due to unhealthy environments: an updated estimate of the global burden of disease attributable to environmental determinants of health. J Public Health p. 1-12.

13. Planning R (2015) Effects of Environmental Degradation on Human Health in Selected Oil Communities in Delta State 5(9): 72-89.

ISSN: 2574-1241

DOI: 10.26717/BJSTR.2018.10.001927

Uttam Paudel. Biomed J Sci \& Tech Res

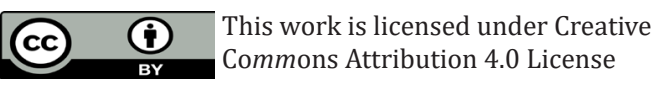

Submission Link: https://biomedres.us/submit-manuscript.php
14. Dror DM, Van Putten Rademaker O, Koren R (2008) Cost of illness: Evidence from a study in five resource-poor locations in India. Indian J Med Res 127: 347-361.

15. Pant KP (2012) Cheaper fuel and higher health costs among the poor in rural Nepal. Ambio 41(3): 271-283.

16. Patz JA, Epstein PR, Burke TA, Balbus JM (1996) Global climate change and emerging infectious diseases. JMMA 75: 217-223.

17. Rogers DJ, Randolph SE (2006) Climate Change and Vector-Borne Diseases. Adv Parasitol 62: 345-381.

18. Ram Dhital S, Koirala M (2016) Climate Change and Its Impacts on Human Health in Nepal. J Heal Educ Res Dev 4: 4-7.

19. Donohoe M (2003) Causes and health consequences of environmental degradation and social injustice. Soc Sci Med 56(3): 573-587.

20. Sattenspiel L (2000) Tropical environments, human activities, and the transmission of infectious diseases. Am J Phys Anthropol.Suppl 31: 3-31.

21. (2018) Nepal - WHO Country Cooperation Strategy (CCS).

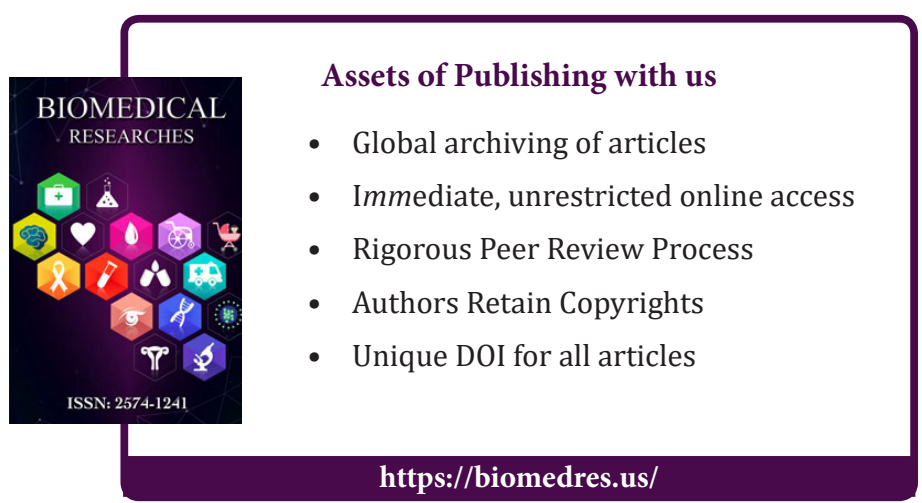

